Estudos de Psicologia

2001, Vol 18, ㄲo 3, 55-73

\title{
Utilização da Discriminação Condicional no Ensino da Literatura e Escrita a Crianças com Paralisia Cerebral
}

\author{
Valíria Rodrigues ${ }^{1}$ \\ José Gonçalves Medeiros ${ }^{2}$
}

\begin{abstract}
O presente estudo está voltado paraaárea da aprendizagem que lida com o comportamento textual- , o comportamento de leitura e escrita, - ensinadaatravés de um procedimento de escolha de acordo com o modelo (matching to sample) e foi desenvolvido com cinco crianças com paralisia cerebral, vinculadas a um serviço de reabilitação e ao ensino regular, sendo quatro com história de repetência, participaram deste trabalho. Os dados demonstram que os procedimentos deescolhade acordo com o modelo, desenvolvidos para ensinar leitura e escrita, conduziram os sujeitos com paralisia cerebral a ler com compreensão, ainda que limitadamente, os textos fornecidos pela professora. Através da observação direta em sala de aula e depoimentos de pais e professores, observou-se, também, algumas mudanças no comportamentoacadêmico dos sujeitosem sala de aula, facilitando sua relação neste contexto e no ambiente familiar.
\end{abstract}

Palavras-chave: discriminação condicional, paralisia cerebral, fracasso escolar.

\begin{abstract}
Matching to Sample to Teach Reading and Writing's Behavior to Children with Cerebral Paralysis

This essay concerns the learning area, which deals with textual behavior in reading and writing that is taught by means of a choice procedure according to a model (matching to sample) and was developed with five children with brain paralysis, who were placed in a rehabilitation center and were students in a standard education public school; four of these children had school failure history. Data show that choice procedures according to a model designed to teach reading and writing, led individuals with brain paralysis to read and understand texts presented by their teacher, though imperfectly. Through reports by parents and teachers ithas been also known that subjects changed their behavior in classroom and home; their relationship to others in those settings has been made easier.
\end{abstract}

Key words: conditional discrimination, brain paralysis, school failure, teaching to read and write.

\section{Introdução}

As limitações físicas apresentadas por crianças com PC, mesmo não se constituindo na "causas" ou "motivos" do fracasso escolar, são apontadas como responsáveis por vários aspec-

tos inadequados do seu cotidiano. Um deles, por exemplo, pode ser observado na dificuldade de acompanhar as atividades acadêmicasque pode ser devida tanto à própria natureza da seqüela (impedindo o indivíduo de freqüentar a escola),

1. Pedagoga da Gerência de Pesquisa e Tecnologia (GETEC) Fundação Catarinense de Educação Especial. Rua Paulino Pedro Hermes, 2785, bairro Nossa Senhora do Rosário - CEP 88108-500 - São José, SC. email: fcee01@email.sc.gov.br. Fones: (48) 381-1648; 381-1675.

O presente artigo originou-se da Dissertação de Mestrado defendida no Programa de Pós-Graduação em Psicologia. $O$ trabalho da autora foi parcialmente financiado pela CAPES através de bolsa de estudo com duração de 12 meses.

2. Professor e orientador do Programa de Pós-Graduação em Psicologia da UFSC. Endereço para correspondência Caixa Postal 5060 - CEP 88040-970 - Florianópolis, SC. e-mail: medeiros@mboxl.ufsc.br.

Fones: (48)381-1648; 381-1675. 
quanto à impossibilidade de acesso físico às salas (existência de barreiras arquitetônicas, falta de acompanhante para as atividades acadêmicas, etc.). Dentre as limitações sociais, encontra-se o estigma como um fator impeditivo do desenvolvimento acadêmico dessas crianças.

Os procedimentos que produzem a formação de classes de equivalência têm implicações educacionais por vários motivos:

a) eles podem tomar possível a ocorrência de comportamento adaptativo em ambientes aos quais o aluno nunca foi exposto (Mackay, 1991);

b) permitem economia na maneira de ensinar, através da emergência de relações condicionais não ensinadas diretamente;

c) fazem com que o ensino possa ser aplicado de forma mais ampla, pois não necessariamente dependem de instruções verbais;

d) permitem verificar se há outras aprendizagens no repertório do sujeito;

e) têm aplicações para indivíduos portadores de várias síndromes com idades variadas e se prestam para ensinar muitas habilidades.

Em termos educacionais, pesquisas em equivalência de estímulos têm ainda contribuído para instalar repertórios comportamentais complexos em uma variedade de indivíduos portadores de deficiência mental, autistas e indivíduos com danos cerebrais de diferentes idades. Por exemplo, alguns estudos estabelecem leitura funcional e/ou soletração (spelling) de palavras simples, fazendo enriquecer o vocabulário dos sujeitos (Mackay e Sidman, 1984; Mackay, 1985; Sidman, 1971; Sidman e Cresson, 1973; Matos e D'Oliveira, 1992).

A vantagem de se utilizar o paradigma de equivalência, segundo Stoddard (1992), é que ele pode auxiliar o professor na descrição e avaliação do desempenho individual do aluno, desempenho este que, muitas vezes, passa despercebido pelo professor que utiliza o método tradicional de ensino. Além das possibilidades do paradigma de equivalência, um ponto a ser destacado aqui diz respeito à natureza dos estímulos empregados nesses estudos e suas implicações para o ensino de leitura e escrita fluentes, como o que foi utilizado nesta pesquisa: as palavras ensinadas foram retiradas do universo vocabular da criança. Na pesquisa realizada por Medeiros, Monteiro e Silva (1997), a escolha das palavras utilizadas constituiu-se num aspecto crítico. Neste estudo, os autores ensinaram palavras pertencentes ao universo vocabular do sujeito, afirmando que, dentre os possíveis fatores que facilitaram o comportamento de leitura, está, provavelmente,

a utilização de palavras que já faziam parte do universo vocabular do sujeito, possibilitando, desta forma, vincular o processo de aprendizagem com a sua realidade (p.75).

Freire (1978), em sua principal obra, "Pedagogia do oprimido", afirma:

Estes temas se chamam geradores porque, qualquer que seja a natureza de sua compreensão como a ação por eles provocada, contém em si a possibilidade de desdobrar-se em outros tantos temas que, por sua vez, provocam novas tarefas que devem ser cumpridas (p.110);

ainda sobre este aspecto

... a investigação do tema gerador... se realizada por meio de uma metodologia conscientizadora, além de possibilitar sua apreensão, insere ou começa a inserir os homens numa forma crítica de pensarem seu mundo (p.113). 
No estudo de Medeiros e cols., o sujeito foi um adulto que freqüentou a 1 a série do 1 음 grau por apenas três meses e abandonou a escola para trabalhar no meio rural, visando o sustento da família. Os autores utilizaram o procedimento de equivalência de estímulos para ensinar o comportamento de leitura e escrita. Ao término do programa, o sujeito apresentou um elevado percentual de leitura com compreensão, tanto de palavras ensinadas como de generalização.

Crianças com deficiência física visíveis (decorrentes da paralisia cerebral), sujeitos deste trabalho, levam desvantagem em relação às demais crianças, com dificuldades de aprendizagem. Por serem estigmatizadas, entre outros motivos, pelo aspecto visual e por apresentarem dificuldades em acompanhar as tarefas cobradas das crianças ditas normais, elas são discriminadas e classificadas como incapazes de aprender, sendo excluídas do processo ensino-aprendizagem. Surgem, assim, os problemas para o professor que, sem uma adequada formação pedagógica (e política), se vê diante de crianças que, na sua opinião, não têm condições de serem alfabetizadas. Pior ainda, pois atribuem a elas o fracasso por causa da deficiência, não conseguindo enxergar que o problema das dificuldades de aprendizagem situa-se basicamente no sistema de interação em sala de aula e, num nível mais amplo, em todo o sistema de relações desenvolvido dentro da instituição de ensino.

Para lidar com problemas desta natureza, a Análise Experimental do Comportamento (AEC) tem desenvolvido procedimentos experimentais de ensino de leitura e escrita em indivíduos com dificuldades de aprendizagem e indivíduos com necessidades educativas especiais. Para Stromer, Mackay e Stoddard (1992), essa abordagem é um conjunto integrado de métodos que deriva da pesquisa denominada equivalência de estímulos. Quando o estímulo inclui palavras, equivalência pode ser livremente definida como aprendizagem daquilo que as palavras significam. Outras formas de comportamento, como escrever e soletrar as palavras, podem também estar envolvidas. Resultados promissores têm sido obtidos, principalmente com crianças em idade escolar(Medeiros e co1s.,1996; Melchiori e cols., 1992.; de Rose e cols., 1989). Os procedimentos têm sido estendidos também a adultos analfabetos (Medeiros e cols., 1997 e Melchiori e cols., 1995) e a uma criança hiperativa e com déficit de atenção (Medeiros e Monteiro, 1996). Em geral, independente da condição do sujeito (criança, adulto ou com necessidades educativas especiais), os procedimentos têm garantido o ensino e promovido alterações de relações comportamentais já estabelecidas, além de propiciar o surgimento de novas relações, principalmente as de generalização. Isto porque os resultados obtidos nos estudos de equivalência são funcionalmente relacionados à história de ensino dos sujeitos e seus efeitos vão além dos repertórios estabelecidos experimentalmente, propiciando, desta maneira, alterações nas relações acadêmicas dos sujeitos.

Pesquisas em equivalência de estímulos têm produzido tecnologia voltada para a instalação de repertórios comportamentais complexos em uma variedade de indivíduos, sendo, portanto, este um dos motivos da escolha desta metodologia para a condução deste trabalho. Muitas destas pesquisas foram conduzidas em laboratórios, e a maior parte da clientela tem sido composta de indivíduos com dificuldades de aprendizagem, porém têm sido poucas as aplicações com indivíduos com necessidades educativas especiais.

No presente trabalho, o comportamento textual de leitura e escrita foi ensinado a crianças com paralisia cerebral (PC), com o propósito de verificar se o ensino das relações $A B$ e $A C$ favoreceria a emergência das relações transitivas $B C$ e CB e classes de respostas de generalização, 
além de oferecer à escola uma alternativa às técnicas tradicionalmente utilizadas para lidar com crianças com esse tipo de problema. O ensino desta habilidade tem-se mostrado problemático para indivíduos com deficiência física, principalmente devido ao atraso no desenvolvimento neuro-psico-motor, originando dificuldades na aquisição de comportamentos acadêmicos.

O estudo ora descrito procurou ensinar leitura e escrita a crianças com PC, na expectativa de que o ensino direto do comportamento textual aumentasse a probabilidade de novos comportamentos de leitura, ou seja, proporcionasse leitura generalizada.

Assim, para atingir o objetivo do presente estudo, desenvolver e sistematizar um procedimento de ensino de relações de leitura e escrita a indivíduos com paralisia cerebral de tal modo que, em sala de aula, pudessem acompanhar, ainda que em ritmo e qualidade diferenciadas, o programa de ensino destinado a uma classe regular, foi realizado um procedimento, apresentado no Método, cuja descrição vem a seguir.

\section{Método}

\section{Sujeitos}

Participaram como sujeitos cinco crianças, com idade entre 7 e 12 anos, com paralisia cerebral $\left(\mathrm{PC}^{3}\right)$ com hemiplegia, hemiparesia e diplegia $^{4}$ que apresentavam dificuldades para acompanhar os conteúdos acadêmicos; dos cinco matriculados na 1 a e $2^{2}$ séries do ensino regular, três estavam também matriculados numa Instituição de Reabilitação.

\section{Local}

O procedimento com três crianças $(F, J$, B) foi realizado na Instituição de Reabilitação, no horário de atendimento do setor pedagógico; com M, o procedimento ocorreu em sua residência após o término das atividades de fisioterapia e das tarefas escolares; com $D$, o procedimento foi realizado numa instituição religiosa que atende crianças carentes fora do horário regular de ensino.

\section{Situação e material}

$\mathrm{O}$ atendimento foi sempre individual, com a experimentadora e os sujeitos sentados um ao lado do outro em uma mesa. Os estímulos visuais foram constituídos de palavras (tipo arial, bold, tamanho 52 do processador do Word 7.0) e de figuras extraídas dos cliparts de um Cd Rom; as letras foram coladas em cubos de madeira,- de $3 \mathrm{~cm}$ de altura por $3 \mathrm{~cm}$ de largura-, os quais foram apresentados aos sujeitos. Em virtude do comprometimento motor dos sujeitos, houve necessidade de modificar o material de montagem ${ }^{5}$. pastas plásticas com os estímulos impressos eram colocadas em um suporte de madeira que ficava em uma posição ligeiramente inclinada, com a folha de registro no lado direito do sujeito,juntamente com os blocos de madeira para a atividade de montagem das palavras.

\footnotetext{
${ }^{3}$ É um termo usado para designar um grupo de desordens motoras e de postura, não progressivas, porém sujeitas a mudanças, resultantes de uma lesão no cérebro nos primeiros estágios de seu desenvolvimento. Esta definição foi proposta por Hagberg em 1989 e aceita pela Sociedade Internacional de Paralisia Cerebral.

${ }^{4}$ Hemiplegia: é o envolvimento de um só lado. Hemiparesia: quando apenas um dos lados do corpo é acometido, podendo ser o direito ou o esquerdo. Diplegia: é o envolvimento do corpo inteiro; a metade inferior, entretanto, é mais afetada que a metade superior. O controle da cabeça, dos braços e mãos é geralmente pouco afetado, e a fala pode ser normal.

${ }^{5}$ Em estudos de equivalência, geralmente as letras são coladas em pedaços de cartolina.
} 


\section{Procedimento}

Antes de iniciar o procedimento, três etapas foram realizadas: a escolha dos sujeitos, a entrevista inicial e o teste de identificação das figuras. A síntese do procedimento encontra-se descrita na Tabela 1.

\section{Escolha dos sujeitos}

A indicação dos sujeitos foi feita, a partir de relatórios, pela pedagoga que acompanhava as crianças no ensino regular; após visita realizada às escolas, constatou-se que os professores estavam com dificuldades de trabalhar com essas crianças principalmente em leitura e escrita. Os sujeitos que não mais estavam em tratamento foram escolhidos pelo fato de terem sido constadas dificuldades em acompanhar a leitura e escrita de suas respectivas escolas.

\section{Entrevista inicial}

O procedimento para coleta de informações consistiu de uma entrevista individual com cada participante, semi-estruturada e com roteiro pré-estabelecido acerca do vocabulário já adquirido e relacionado às informações que fazem parte da vida do sujeito (perguntas sobre o corpo humano, família, escola, alimentos, lazer e escolhas pessoais). O material utilizado pela experimentadora foi composto de um caderno e uma caneta. Antes de iniciar a entrevista, a experimentadora informou que anotaria todas as suas respostas, como faz um jornalista, onde ele seria o entrevistado e, ela, a entrevistadora.

As palavras concretas e dissílabas que apareceram na e77777ntrevista foram organizadas em uma lista e apresentadas aos sujeitos, num teste de leitura, para verificar quais delas eles tinham condições de ler. As palavras que

Tabela 1. Quadro-sintese do procedimento.

\begin{tabular}{|c|c|c|c|c|c|}
\hline & & & & Reforc: & nento \\
\hline Fases & Etapas & Conteuido & Sujeitos & Sim & Não \\
\hline \multirow[t]{4}{*}{$\begin{array}{l}\text { [A] Linha de } \\
\text { Base I (LBI) }\end{array}$} & Pré-Teste & $\begin{array}{l}\text { de identificą̧ăo das figuras } \\
\text { de leitura das novas palavras }\end{array}$ & Todos & & $x$ \\
\hline & Aprendizagem & de leitura das novas palavras & Todos & $x$ & \\
\hline & Pós-Teste & de leitura das palavras ensinadas & Todos & & $x$ \\
\hline & Pre-Teste & $\begin{array}{l}\text { de identificaçũo das figuras } \\
\text { de leitura das novas palavras } \\
\text { de leitura das palavras ensinadas na LBI } \\
\text { sondas de leitura das palavras de generalizaç̃o }\end{array}$ & Todos & $\mathbf{x}$ & \\
\hline \multirow[t]{4}{*}{ [B] Exclusâa } & Aprendizagem & $\begin{array}{l}\text { de leitura das novas palavras } \\
\text { sondas de leitura das palavras de generalizaçâo }\end{array}$ & Todos & $\mathbf{x}$ & \\
\hline & Montagem & das novas palavras & Todos & $\mathrm{x}$ & \\
\hline & Retreino & $\begin{array}{l}\text { de leitura e montagem das novas } \\
\text { palavras com acertes abaixo de } 50 \%\end{array}$ & Sujeitos D e B & $x$ & \\
\hline & Pós-Teste & $\begin{array}{l}\text { de leitura das palavras ensinadas } \\
\text { sondas de leitura das palavras de generalizaçảo }\end{array}$ & Todos & $\mathbf{x}$ & \\
\hline$|C|$ Equivalência & Teste & $\begin{array}{l}\text { de identificação das figuras } \\
\text { da relaçio figura/palavra impressa } \\
\text { da relaç̃o palavra impressa'figura }\end{array}$ & Todos & $\mathrm{x}$ & \\
\hline $\begin{array}{l}\text { [D] Teste extensivo } \\
\text { de leitura }\end{array}$ & Teste & $\begin{array}{l}\text { das palavras ensinadas } \\
\text { das palavrus de generalização }\end{array}$ & Todos & & $x$ \\
\hline $\begin{array}{l}\text { [E] Teste de leitura } \\
\text { através de textes }\end{array}$ & Teste & $\begin{array}{l}\text { Textos organizados com palavras dos textos da sala } \\
\text { de aula, das palayras ensinedas e das palavras de } \\
\text { generalizaçän do procedimento. }\end{array}$ & Sujeitos M, F e J & & $x$ \\
\hline
\end{tabular}


não foram lidas corretamente constituíram a lista das que foram ensinadas. Nesta atividade nenhum tipo de conseqüência reforçadora foi apresentado, mesmo que as respostas estivessem corretas.

\section{Teste de identificação das figuras}

Para cada palavra escolhida, foi também selecionada a figura correspondente e apresentada ao sujeito, seguindo um procedimento similar àquele do teste de leitura. A experimentadora apontava um desenho de cada vez e perguntava: "O que é isto?" E anotava a resposta do sujeito, evitando corrigi-lo.

\section{Descrição geral do procedimento}

O procedimento principal, um delineamento do sujeito como seu próprio controle, foi o de escolha de acordo com o modelo, usado para expandir gradualmente, ao longo de uma seqüência de passos, o repertório de pareamentos entre o modelo (palavra ditada pelo experimentador) e o estímulo de comparação (palavra impressa). O procedimento tem como base a presença, em cada tentativa de pareamento, de um estímulo de comparação, conhecido pelo sujeito, que foi apresentado juntamente com outro estímulo, desconhecido pelo sujeito. Quando o experimentador apresentou o modelo correspondente ao estímulo novo, o estímulo de comparação já conhecido funcionou como pista ou dica para que o sujeito rejeitasse e selecionasse corretamente o estímulo novo. Dessa forma, neste programa, o procedimento permitiu a aprendizagem sem erro do pareamento de palavras ditadas com palavras impressas.

O programa envolveu também a presença de sondas para verificar a leitura de palavras não diretamente ensinadas (palavras de generali- zação), realizada nas etapas do pré e pós-teste, bem como na etapa de exclusão. Na exclusão, a sondas foram apresentadas, em média, após quatro a cinco tentativas de ensino das novas palavras. O programa foi dividido numa seqüênciade passos, sendo os dois primeiros destinados à aquisição de uma linha de base inicial que, à medida que o procedimento de exclusão se expandia, foi sendo ampliada. O programa prosseguiu alternando passos de exclusão com passos de equivalência, nos quais foi verificada a formação de classes de equivalência entre palavras faladas, palavras impressas e figuras.

As tentativas iniciais de um passo de exclusão consistiram num pré-teste que avaliou a leitura das palavras de ensino introduzidas no passo, das palavras ensinadas nasessão imediatamente anterior e também a leitura de palavras de generalização. As tentativas finais do passo constituíram-se num pós-teste usado para avaliar as palavras ensinadas na sessão, bem como a leitura das palavras de generalização. A identificação correta das palavras ensinadas na sessão anterior constituiu um requisito para aplicação de um passo; quando o critério não era atingido, o passo anterior era repetido. Três testes extensivos de leitura foram aplicados para avaliar o percentual de retenção de leitura das palavras ensinadas, bem como das palavras de generalização. O primeiro teste foi realizado após a exclusão 10, o segundo após a exclusão 15 e o terceiro após a exclusão 21. Porém, com dois sujeitos $(D, B)$, houve necessidade de realizar testes parciais, que ocorreram a cada três exclusões, pois a retenção de leitura com esses sujeitos foi inferior à dos demais.

Cinco procedimentos básicos fizeram parte do procedimento: Linha de Base I, Linha de Base II (Equivalência), Exclusão, Equivalência e Teste. O procedimento foi realizado com material programado, respeitando-se 0 
ritmo individual dos sujeitos, porém passava-se para a etapa posterior quando, na anterior, se alcançava $100 \%$ de acertos. Os reforçadores utilizados foram de natureza social, com expressões tipo "muito bem", "isso mesmo", "correto". Durante o procedimento, contudo, houve necessidade de modificar a contingência de reforçamento para os sujeitos $\mathrm{D}$ e B. Até a sessão 10 foi utilizado apenas o reforço social. A partir dessa sessão, na montagem das palavras, os sujeitos passaram a receber, além do reforço social, uma ficha plástica ${ }^{6}$ colorida se a montagem da palavra estivesse correta. Contudo, na leitura da palavra, apenas o reforço social foi apresentado. No final do procedimento a experimentadora pedia ao sujeito que contasse quantas fichas havia recebido, pois poderia comprar material escolar que a experimentadora expunha na mesa com os valores de cada um.

\section{Fase de linha de base I}

\section{(como visto em [A] no quadro-síntese)}

Etapa do pré-teste das palavras de ensino e das figuras correspondentes

Nesta etapa, três palavras de ensino e as figuras correspondentes foram apresentadas a cada sujeito. Ao iniciar a sessão, abria-se a pasta plástica contendo as palavras impressas (uma em cada folha) e apresentava-se à criança a primeira palavra, dizendo-se: "Que palavra é essa?" Nenhuma conseqüência foi fornecida para o acerto ou erro da criança, com a experimentadora agindo com a maior neutralidade possível e prosseguindo com as outras duas palavras.

\section{Etapa de aprendizagem}

Iniciou-se a Fase de Linha de Base I com o ensino de três palavras que a criança não sabia ler. Cada palavra de ensino foi apresentada, junto com a instrução: "Esta palavra é copo", "Que palavra é essa?", "Aponte a palavra copo". Se o sujeito apontasse corretamente a palavra, ele era elogiado com expressões do tipo "muito bem", "parabéns", "correto"; o mesmo ocorria, também, se o sujeito a verbalizasse corretamente. Caso a resposta fosse incorreta, o procedimento era repetido até que a resposta fosse verbalizada corretamente. A resposta era assinalada como certa ou errada na respectiva coluna da folha de resposta. Assim que uma das palavras tivesse sido ensinada, duas das três palavras de ensino eram apresentadas de cada vez, sendo uma delas a palavra já ensinada), perguntando-se ao sujeito qual era a palavra desconhecida e pedindo-lhe para apontá-la (por exemplo "aponte cama"). Quando apontada corretamente, era elogiado. Após ter apontado a palavra solicitada, a experimentadora solicitava que dissesse qual era a outra (sendo reforçado se acertasse).

Após o ensino da primeira palavra, dava-se início ao procedimento de montagem dessa palavra, dizendo: "Então, agora, você vai escrever com essas letras, apalavra copo". Se a montagem fosse correta, esta era consequenciada positivamente com expressões do tipo: "Isso", "Muito bem", "Parabéns". Na seqüência, a experimentadora perguntava: "Que palavra você escreveu?" Se o sujeito lesse a montagem corretamente, era novamente reforçado. $\mathrm{O}$ mesmo procedimento ocorreu com as outras duas palavras. Se não realizasse corretamente a montagem, a experimentadora pedia para tentar outra vez: "Vamos tentar mais uma vez?" Caso o sujeito não conseguisse montar a palavra na primeira tentativa, era sugerido: "Olhe bem como você escreveu a palavra (a experimentadora apontava a palavra impressa). Vamos tentar escrever a palavra novamente".

6. Semelhantes a fichas de jogos de baralho. 


\section{Etapa do pós-teste}

Terminada a etapa de ensino, as palavras eram novamente apresentadas ao sujeito com a experimentadora dizendo: "Então vou mostrar-Ihe as palavras que você aprendeu e não vou dizer se a sua resposta está certa ou errada" e era solicitado para dizer o nome de cada uma, apresentada individualmente, dizendo: "Aponte e diga que palavraé esta". Em seguida, perguntava: "Qual é a outra?" Então a experimentadora anotava as respostas na folha de registro e nenhuma conseqüência era apresentada contingentemente ao acerto ou erro. Foram seis tentativas com três palavras apresentadas em cada folha.

\section{Fase de exclusão}

\section{(como visto em [B] no quadro-síntese)}

\section{Etapa do pré - teste das novas palavras de ensino e das respectivas figuras}

Repetia-se o procedimento da Etapa 1 da Fase A (Linha de Base I), acrescido de três palavras de generalização (fonnadas a partir da composição das sílabas das palavras já ensinadas). A criança tinha que identificar corretamente (100 \% de acerto) todas as palavras já ensinadas (retenção) na sessão anterior. Se isso não ocorresse, repetia-se novamente a sessão na qual aquelas palavras foram ensinadas.

\section{Etapa de aprendizagem}

No ensino da primeira palavra, esta foi sempre apresentada juntamente com uma das palavras já ensinada na fase anterior, acompanhada das perguntas: "Qual das palavras é... ?", "Que palavra é esta"?, E dizia o nome da palavra nova, colada na base da folha, ao lado da palavra conhecida, solicitando que a apontasse. Nessa situação, o estímulo-modelo era a palavra falada (estímulo auditivo) e os estímulos de comparação eram as palavras impressas (coladas na base da folha de papel). Se o sujeito respondesse identificando corretamente a palavra, era elogiado com expressões do tipo "muito bem", "parabéns", etc.; caso a resposta fosse incorreta, era usado um procedimento de correção, perguntando: "Você tem certeza?". Caso o sujeito alterasse sua resposta, aplicava-se o procedimento regular de reforço das tentativas corretas.

A cada quatro tentativas de ensino, três palavras de generalização ${ }^{7}$ foram apresentadas como sondas de leitura. Uma tentativa de sonda constava de uma palavra colada em uma folha; a experimentadora apresentava a referida folha e perguntava "Que palavra é essa?", sem apresentar qualquer conseqüência à resposta do sujeito. Em cada exclusão três palavras dissílabas $^{8}$ eram ensinadas. Após o sujeito ter atingido o critério de acertos que consistia de $100 \%$ de leitura correta das palavras que estavam sendo ensinadas (Exclusão e Pós-teste), passava-se para a próxima exclusão, onde outras três palavras eram ensinadas.

\section{Etapa de montagem (cópia)}

Tentativas de montagem foram também realizadas. A experimentadora distribuía as letras (que compunham a palavra a ser montada) aleatoriamente sobre a mesa e solicitava ao sujeito que montasse a palavra semelhante àquela que estivesse sendo ensinada (um dos estímulos de comparação). Após o sujeito ter montado a palavra corretamente, aplicava-se 0 procedimento regular de reforço e solicitava-se que lesse a palavra que acabara de montar.

\section{Etapa do pós-teste das palavras ensinadas} na exclusão e das palavras de generalização

Após terminar a etapa de ensino das novas palavras de exclusão, estas eram cobertas por um cartão, com a experimentadora dizendo: "Agora vou mostrar-Ihe essas palavras e não vou Ihe dizer se estão certas ou erradas". Solicitava-se ao sujeito para dizer o nome de uma

7. Montadas a partir da sílabas que compunham as palavras da exclusão anterior.

8. Posteriormente, palavras trissílabas foram também acrescentadas. 
das palavras, dizendo: "Aponte e leia a palavra..." (dizia uma das palavras que foi ensinada). Em seguida, dizia: "Aponte e leia a outra palavra". Nenhuma conseqüência era fornecida ao desempenho do sujeito.

Fases de Retreino (reapresentação das palavras j á ensinadas) foram realizadas toda vez que o percentual de acertos obtido nos testes extensivos de leitura fosse abaixo de $50 \% \%^{9}$.O procedimento foi semelhante ao da Etapa de Exclusão. Foram ensinadas novamente as palavras lidas incorretamente, o que, no caso dos sujeitos $D$ e $B$, englobou palavras da Linha de Base I até a Exclusão 10; no final do Retreino foi realizado novo teste extensivo de leitura.

\section{Fase de equivalência (como visto em [C] no quadro-síntese)}

\section{Teste de identificação das figuras}

Antes de dar início à fase de equivalência, apresentavam-se as figuras correspondentes às palavras de ensino, uma de cada vez, perguntando-se: "Que figura é esta?" Não se reforçava a identificação correta das figuras; quando o sujeito não identificasse corretamente a figura, a experimentadora Ihe perguntava novamente a seguir: "O que é isto?"

\section{Nome da figura como estímulo-modelo}

Nesta fase do procedimento, o nome da figura funcionou como estímulo-modelo e as figuras como estímulos de comparação, sendo um deles o correto ou aquele que correspondia ao estímulo-modelo.

A princípio, um cartão cobria os estímulos de comparação. Solicitava-se ao sujeito que apontasse para o nome da figura colada no alto da página; tendo apontado, retirava-se o cartão que cobria os estímulos de comparação e pedia-se que apontasse para a figura que correspondesse ao estímulo-modelo: "Agora, aponte afigura". Assim que tivesse apontado, era-lhe perguntado: "Que figura é esta?" Então anotava-se sua resposta e nenhuma conseqüência era fornecida ao seu desempenho, não importando se a resposta estivesse correta ou incorreta.

\section{Figura como estímulo-modelo}

Neste caso, uma das figuras funcionava como estímulo-modelo e os nomes das figuras como estímulos de comparação, sendo um deles o correto. Os estímulos de comparação (os nomes) eram cobertos por um cartão, enquanto era-Ihe dito: "Aponte a figura. Que figura é essa?" Assim que a criança tivesse apontado e verbalizasse o nome da figura, pedia-se-lhe para repetir: "Agora aponte o nome correto" e nenhuma conseqüência foi fornecida ao desempenho do sujeito, não importando se a resposta estivesse correta ou incorreta.

\section{Fase de testes extensivos de leitura (como visto em [D] no quadro-síntese)}

Testes extensivos de leitura foram realizados para verificar a leitura de todas as palavras de ensino e generalização introduzidas até o referido passo. O primeiro teste foi realizado após a exclusão 10, o segundo após a exclusão 15 e o terceiro após a exclusão 21.

\section{Teste de leitura através de textos (como visto em [E] no quadro-síntese) \\ Sujeito M}

Emuma das observações do desempenho acadêmico de $\mathrm{M}$, em sala de aula, a professora explicou um assunto relativo à água potável e, logo em seguida, transcreveu-o na lousa. $M$ perguntou para a professora se copiava o texto, ao que a professora respondeu que não, pois sua acompanhante copiava os textos de sala de aula para que, em casa, M pudesse copiá-los; enquanto a acompanhante realizava a cópia, $M$ lia o texto do quadro. Foi, portanto, no trans-

9. Dois sujeitos (D e B) participaram deste procedimento. 
correr deste episódio de leitura que se notou dificuldade de $\mathrm{M}$ na leitura de textos; no dia seguinte, no momento da aplicação do procedimento, foi realizado um teste de leitura com o texto dado em sala de aula. Ao verificar as dificuldades de leitura, iniciou-se, então, a composição de textos específicos para serem apresentados e testados com M; partindo, portanto, das palavras que não conseguiu ler no texto dado em sala de aula, organizaram-se os demais (de 1 a 11), acrescentando palavras de ensino e palavras de generalização do procedimento de exclusão.

\section{Sujeitos $\mathrm{F}$ e $\mathrm{J}^{10}$}

Ao encerrar o procedimento de ensino de palavras com os sujeitos $F$ e J, foram apresentados dois textos, organizados com algumas palavras de ensino e palavras do cotidiano da criança, com o objetivo de verificar a possibili- dade do ensino de leitura através de textos; após a leitura dos textos, foram formuladas questões para verificar se tinham compreendido a leitura.

\section{Resultados $^{11}$}

A Figura 1 apresenta o percentual de leitura correta das palavras de ensino (parte superior da figura) e das palavras de generalização (parte inferior da figura) do sujeito D. É possível observar, na etapa do pré-teste, uma ampla faixa de variabilidade, com valores entre 0 e $100 \%$ de leitura correta, com cinco sessões dentro da área critério; já, na aprendizagem, o nível de acertos mantém-se praticamente em $100 \%$, com todos os valores percentuais localizados dentro da área critério. No pós-teste, a variação, bem menos acentuada que no pré-teste, oscila entre $67 \mathrm{e}$ $100 \%$, com 38 sessões dentro da área critério.

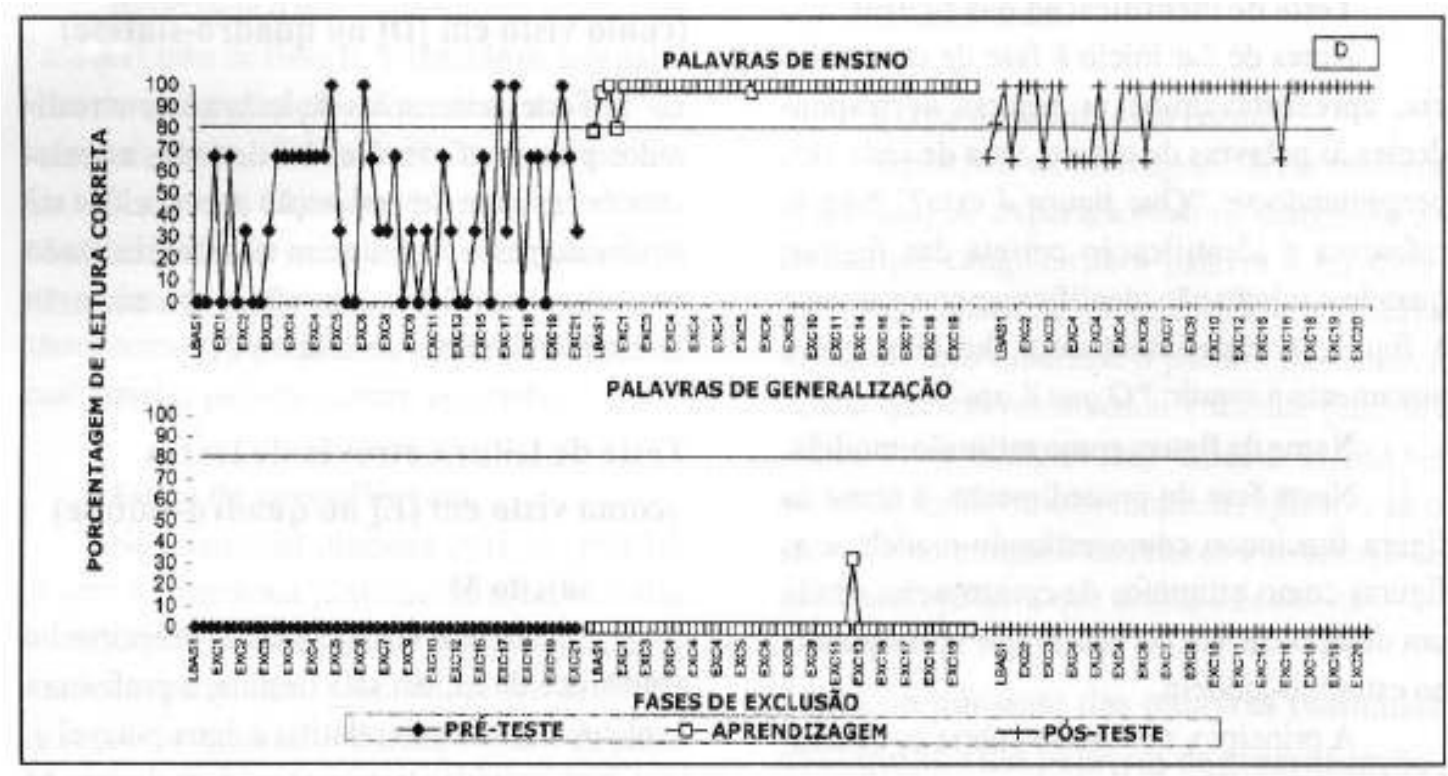

Figura 1. Porcentagem de leitura correta das palavras de ensino (parte superior) e das palvras de generalização (parte inferior) nas etapas (pré-teste, aprendizagem e pós-teste) da exclusão do sujeito D.

10. Com os sujeitos de B não foi possível verificar a compreensão de leitura através de textos, devido ao fato de apresentarem dificuldades de leitura com algumas palavras de ensino no procedimento de exclusão e de não ter ocorrido leitura correta das palavras de generalização.

11. A área do gráfico localizada entre 80 e 100\% foi denominada de "área critério"; assim, os valores percentuais localizados nesta área foram considerados como indicativos de que a leitura do sujeito está sob controle das variáveis do procedimento. 
Em relação às palavras de generalização, não há, praticamente, nenhum indício de leitura, exceto na EXC 13, onde D apresenta, na etapa de aprendizagem, $40 \%$ de leitura generalizada; nas demais exclusões, o sujeito dizia "não sei"; em algumas exclusões, quando as palavras de ensino e generalização estruturalmente se assemelhavam, o sujeito repetia as sílabas que eram comuns entre as palavras; assim, por exemplo, na EXC 15, frente à palavra "luva" (de generalização), leu "uva" (palavra de ensino).

A Figura 2 apresenta o percentual de leitura correta das palavras de ensino (parte superior da figura) e das palavras de generalização (parte inferior da figura) de F. Pode ser observado, na etapa do pré-teste, uma variação entre zero e $100 \%$ de leitura correta, com três sessões dentro da área critério; na etapa da aprendizagem, assim como na etapa do pós-teste, o percentual de acertos mantém-se em $100 \%$, com todas as sessões localizadas dentro da área critério.
Em relação às palavras de generalização não se observa, nas primeiras 10 sessões do pré-teste, qualquer indício de generalização; observam-se, a partir da 11a EXC, mesmo com acentuada variabilidade, as primeiras tentativas de leitura generalizada, com três sessões localizadas dentro da área critério; na etapa de aprendizagem, verifica-se que o desempenho do sujeito fica sob controle do procedimento mais cedo do que no pré-teste: a EXC2, desta etapa, já apresenta 33\% de leitura correta; nas quatro exclusões seguintes, o percentual de acertos é zero; contudo, pode-se observar, a partir da 7a EXC, que o desempenho do sujeito volta a ficar sob o controle do procedimento com taxas crescentes de acertos, com sete sessões dentro da área critério. O desempenho no pós-teste é muito semelhante ao desempenho verificado na aprendizagem, com taxas baixas (entre zero e $33 \%$ ) no início da etapa e sessões com taxas crescentes de acertos a partir da 9a EXC, de tal modo que se podem observar oito sessões dentro da área critério.

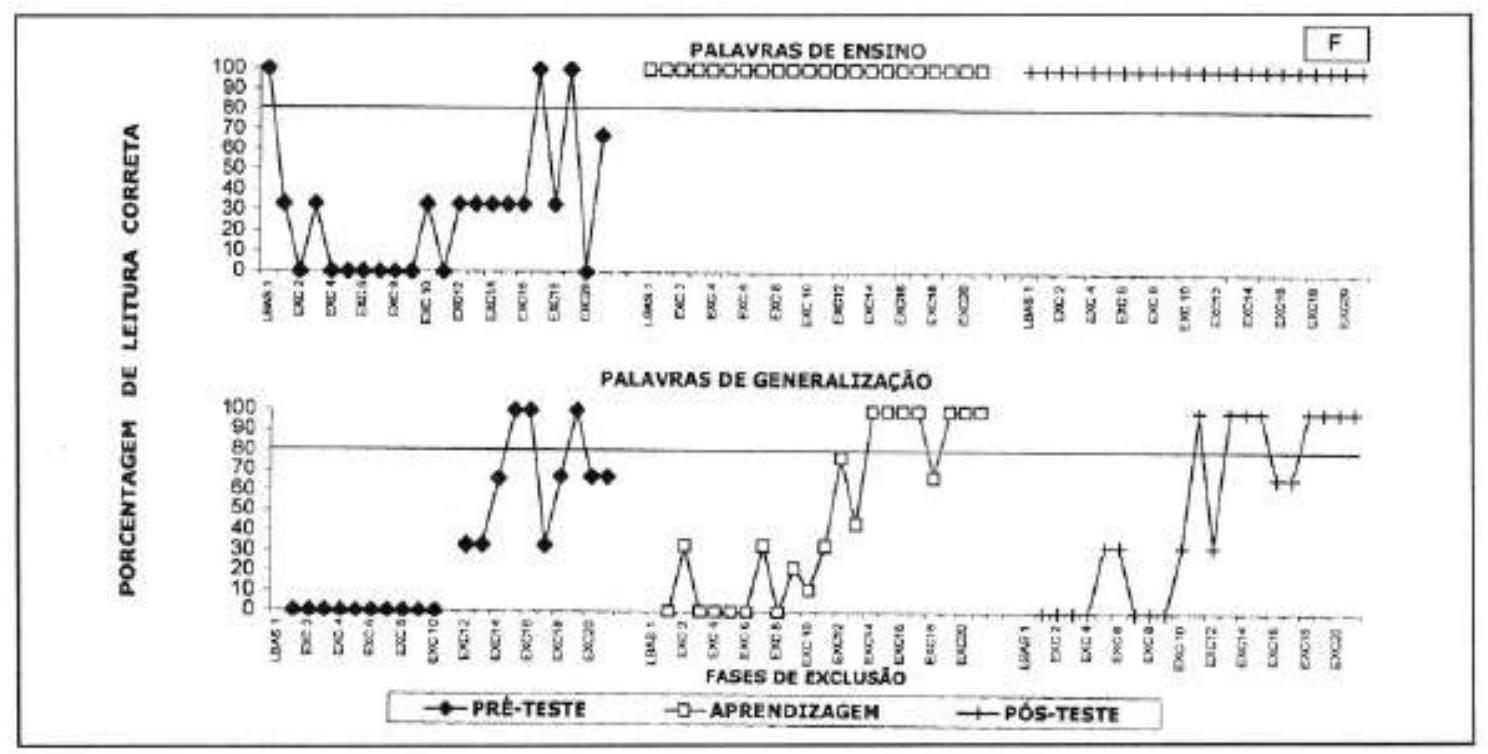

Figura 2. Porcentagem de leitura correta das palavras de ensino (parte superior) e das palavras de generalização (parte inferior) nas etapas (pré-teste, aprendizagem e pós-testes) da exclusão do sujeito $F$. 


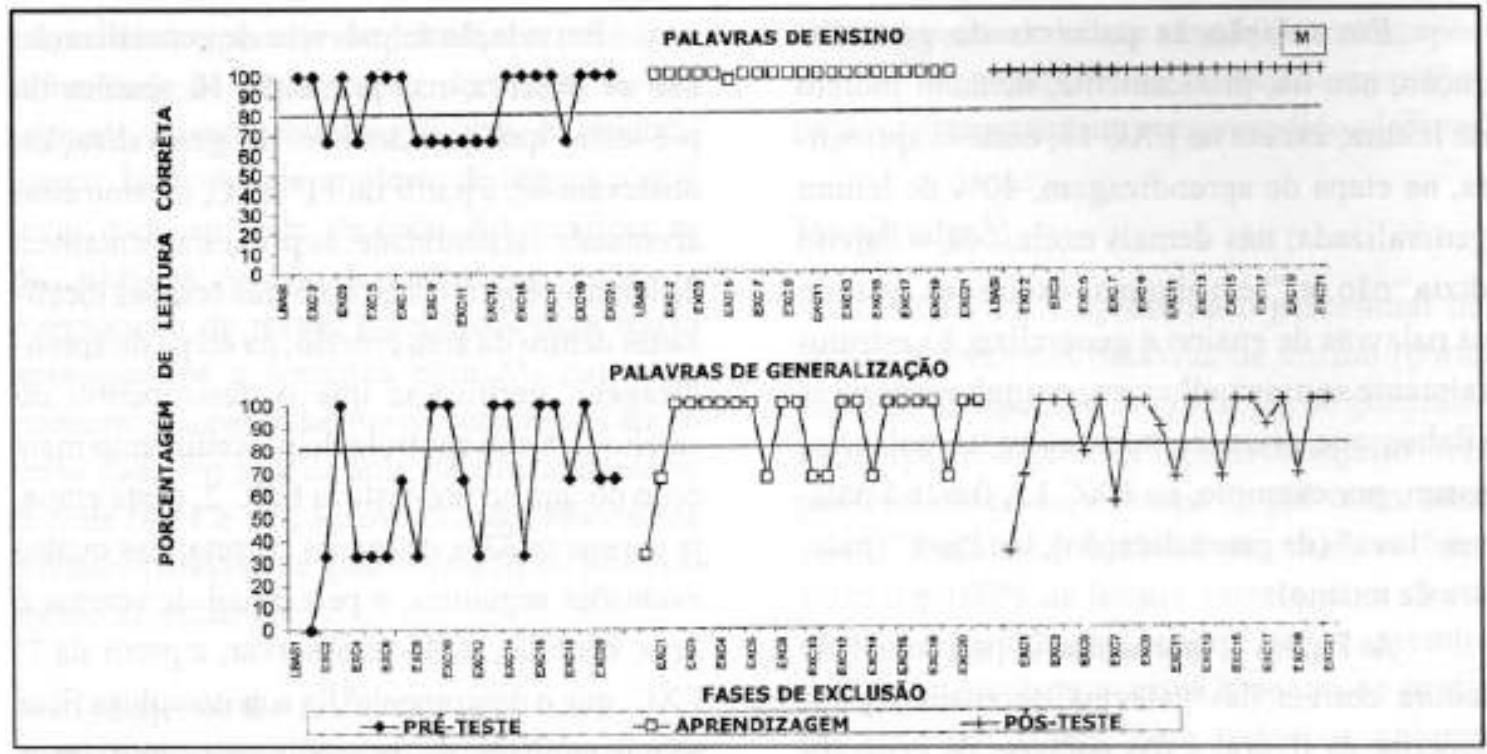

Figura 3. Porcentagem de leitura correta das palavras de ensino (parte superior) e das palavras de generalização (parte inferior) nas etapas (pré-teste, aprendizagem e pós-teste) da exclusão do sujeito $\mathrm{M}$.

A Figura 3 apresenta os dados referentes ao sujeito M. Na etapa do pré-teste das palavras de ensino, os percentuais de acertos situam-se entre 68 e $100 \%$ de leitura correta, sendo que, das 21 sessões, 13 encontram-se dentro da área critério; já, em relação às etapas de aprendizagem e pós-teste, o nível de acertos mantém-se em 100\%, com as porcentagens de todas as sessões localizadas dentro da área critério.

Em relação às palavras de generalização, o sujeito apresenta, a partir da $2^{\mathrm{a}}$ sessão do pré-teste, $33 \%$ de leitura correta; mesmo com grande variabilidade, ocorre, a partir desta sessão ( $2^{\mathrm{a}}$ ),um aumento de sessões com percentuais de acertos mais elevados, resultando em oito sessões dentro da área critério; na etapa de aprendizagem a variabilidade é menor, com a maior parte dos valores entre 67 e 100\%;das 21 sessões realizadas, 16 encontram-se dentro da área critério. O desempenho no pós-teste é muito semelhante ao desempenho apresentado na aprendizagem,com 15sessões dentro da área critério.
A Figura 4 apresenta o percentual de leitura correta das palavras de ensino (parte superior da figura) e das palavras de generalização (parte inferior da figura) de J. É possível observar, na etapa do pré-teste, taxas com variação entre zero e $33 \%$ nas primeiras seis exclusões; a partir desta exclusão, verifica-se que aumenta o controle de estímulos sobre o desempenho do sujeito, com a taxa variando entre 67 e $100 \%$, resultando em 13 sessões dentro da área critério; já, nas etapas de aprendizagem e do pós-teste, o nível de acertos mantém-se em 100\%, com todos os valores percentuais localizado dentro da área critério.

Em relação às palavras de generalização, verifica-se uma acentuada variabilidade nas primeiras nove exclusões do pré-teste, com a porcentagem de leitura correta variando entre zero e $100 \%$; a partir da $10^{\mathrm{a}} \mathrm{EXC}$, a variabilidade diminui acentuadamente, com a porcentagem variando entre 67 e 100\%, resultando em 12 sessões dentro daárea critério; na etapa da aprendizagem, tanto quanto a estapa do pós-teste, a variabilidade nas primeiras nove exclusões é 


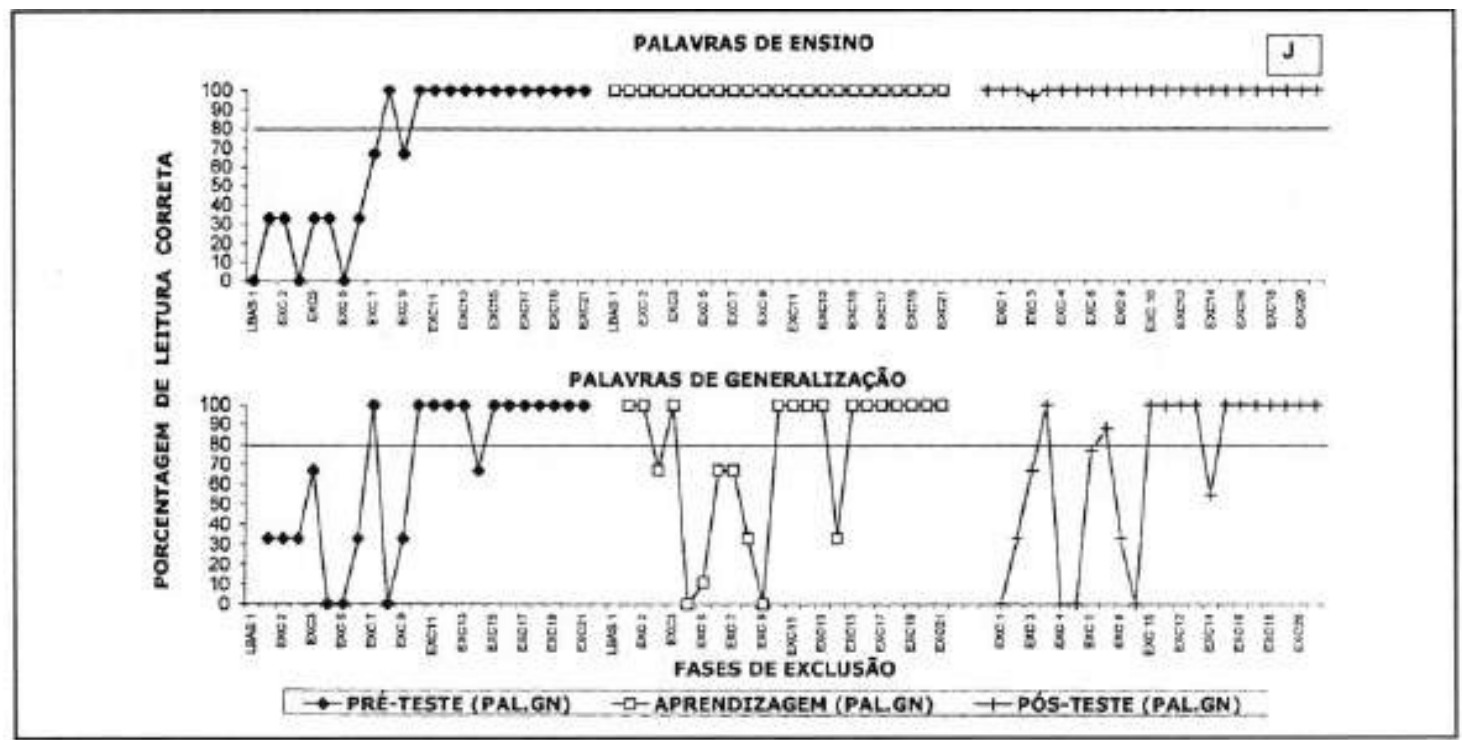

Figura 4. Porcentagem de leitura correta das palavras de ensino (parte superior) e das palavras de generalização (parte inferior) nas etapas (pré-teste, aprendizagem e pós-teste) da exclusão do sujeito $\mathrm{J}$.

muito semelhante à variabilidade verificada na etapa do pré-teste; a partir da $10^{\text {a }}$ EXC, a variabilidade diminui em ambas as etapas, oscilando entre 33 e 100 na aprendizagem, com 14 exclusões dentro da área critério e entre 67 e $100 \%$ no pós-teste, com 13 dentro da área critério.
A Figura 5 apresenta o percentual de leitura correta das palavras de ensino (parte superior da figura) e das palavras de generalização (parte inferior da figura) do sujeito $\mathrm{B}^{12}$. Em relação às palavras de ensino, é possível observar, na etapa do pré-teste, uma grande variabilidade

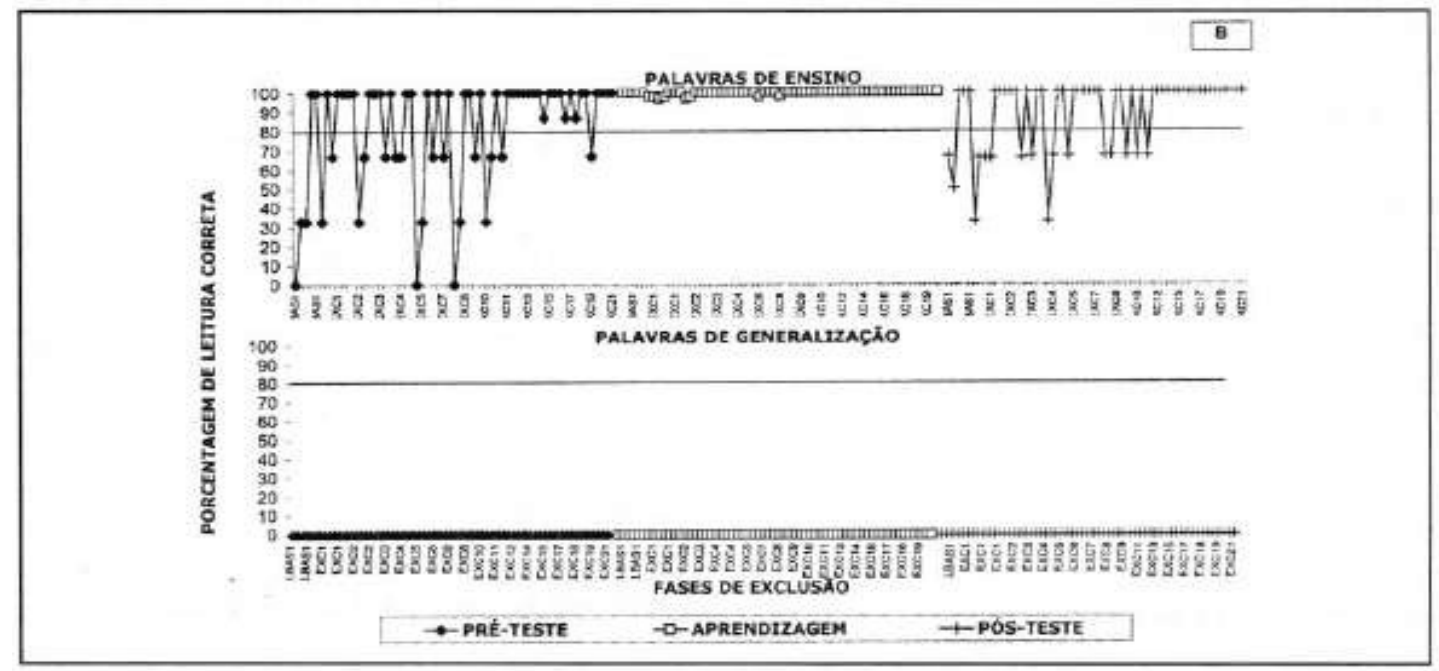

Figura 5. Porcentagem de leitura correta das palavras de ensino (parte superior) e das palavras de generalização (parte inferior) nas etapas (prẻ-teste, aprendizagem e pós-teste) da exclusão do sujeito $B$.

12. Para este sujeito, o número de sessões foi maior que os demais sujeitos, pois houve interrupções devido às faltas e à necessidade de se repetir várias vezes a mesma exclusão 
que se estende da Linha de Base até a EXC 11; os valores percentuais variam entre 0 e $100 \%$. A partir da EXC 12, até o final da etapa, a variabilidade diminui, e os valores percentuais situam-se entre 67 e 100\%, resultando em 37 sessões dentro da área critério; na aprendizagem, o nível de acertos mantém-se praticamente em $100 \%$, com todos os valores percentuais localizado dentro da área critério. No pós-teste, a variabilidade é bem menos acentuada do que no pré-teste, com os valores percentuais oscilando entre 33 e 100\%,com 41 sessões dentro da área critério.

Na parte inferior da Figura 5, pode-se verificar que o sujeito não apresenta leitura generalizada em nenhuma das exclusões; nas últimas houve indícios de generalização, por exemplo, em relação à palavra "feroz" (GEN), lida como "arroz" que foi a palavra ensinada na etapa da aprendizagem; mesmo na fase de retreino não conseguiu ler corretamente nenhuma das palavras de generalização.

Na Figura 6, encontram-se os resultados obtidos nos três testes extensivos de leitura das palavras de ensino (parte superior) e de generalização (parte intermediária) dos sujeitos M, F e J. Em relação às palavras de ensino, $M$ apresenta porcentagem de leitura correta crescente nos testes (80 no Teste 1, 83 no Teste 2 e 98 no Teste 3); os sujeitos F e J apresentam porcentagem de leitura correta entre 96 e 100\%. Em relação às palavras de generalização, assim como em relação às palavras de ensino, a porcentagem de leitura correta de M é também crescente (50 no Teste 1, 74 no Teste 2 e 93 no Teste 3); a porcentagem de leitura correta dos sujeitos F e J situa-se entre 87 e 95\%.

Os testes dos sujeitos D e B foram mais freqüentes em virtude da dificuldade para reterem quantidade alta de palavras; ao contrário dos sujeitos M, F e J, não apresentam leitura generalizada. O histograma, localizado na parte

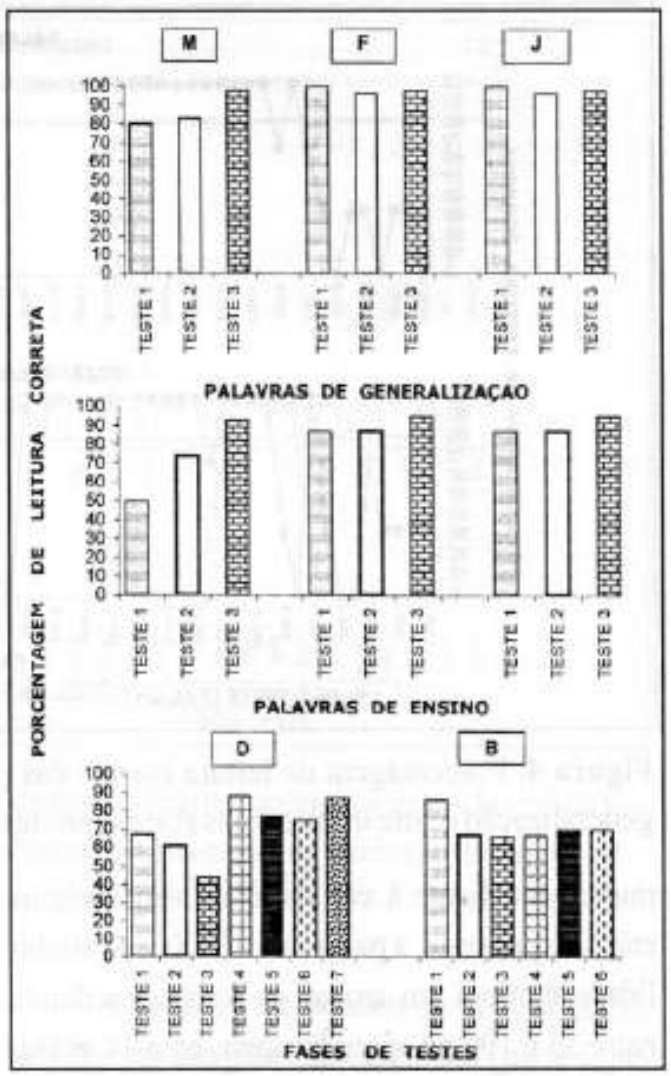

Figura 6. Porcentagem de leitura correta nas fases dos testes extensivos de leitura das palavras de ensino (parte superior) e de generalização (parte mediana) dos sujeitos $\mathrm{F}, \mathrm{M}$ e J e palavras dos sujeitos D e B (parte infeiror).

inferior da Figura 6, mostra que o desempenho de $D$ nos quatro últimos testes (valores entre 75 e $88 \%$ ) é superior aos três primeiros (valores entre 44 e 67\%); o desempenho de B é mais elevado no primeiro teste (86\%) do que nos seis testes seqüenciais (cujos valores percentuais situam-se entre 66 e 75\%).

\section{Testes de leitura com interpretação}

A porcentagem de acertos de $\mathrm{M}$ varia entre 76 e $94 \%$, com um texto com $76 \%$, sete textos entre 80 e $90 \%$ e quatro textos entre 90 e $94 \%$, indicando, deste modo, que o sujeito aprendeu a ler, mesmo considerando que as 
respostas de interpretação às perguntas formuladas foram dadas sem muita certeza (nos primeiros textos $M$ perguntava se poderia ler 0 texto novamente até encontrar a resposta; a experimentadora the permitia fazer duas leituras antes de realizar as perguntas de interpretação e, a partir do $5^{\circ}$ texto, passou a responder sem perguntar nada para a experimentadora, dizendo "eu sei responder esta pergunta").

\section{Discussão}

Os resultados obtidos demonstram que o procedimento de ensino utilizado propiciou leitura e escrita compreensivas a três das cinco crianças com paralisia cerebral; às outras duas propiciou apenas leitura textual. As informações adicionais obtidas a respeito de seus desempenhos no contexto da sala de aula e fora

Tabela 2: Porcentagem de leitura correta de $\mathrm{M}$ (textos de 1 a 11) nos testes de leitura, com textos utilizados em sala de aula e de J e F (textos 1 e 2), com textos montados a partir das palavras de ensino e de generalização.

\begin{tabular}{|c|c|c|c|c|c|}
\hline \multicolumn{3}{|c|}{ Sujeito M } & \multicolumn{3}{c|}{ Palavras } \\
\hline Textos & Titulo & & Total & Acertos & $\%$ \\
\hline 1 & A água e a vida & 118 & 96 & 81 \\
\hline 2 & A festa das criancas & & 34 & 26 & 76 \\
\hline 3 & As frutas & & 55 & 48 & 87 \\
\hline 4 & Papai & & 42 & 36 & 86 \\
\hline 5 & Dia de festas & & 53 & 79 & 93 \\
\hline 6 & A escola & & 41 & 53 & 91 \\
\hline 7 & A casa de Mariana & & 36 & 35 & 85 \\
\hline 8 & Mamåc & & 40 & 34 & 94 \\
\hline 9 & Lanche na escola & & 49 & 41 & 85 \\
\hline 10 & Achuval & & 138 & 128 & 93 \\
\hline 11 & Um dia de sol & & & & \\
\hline
\end{tabular}

\begin{tabular}{|c|c|c|c|c|c|}
\hline Sujeito F \\
\hline 1 & Mamãe e papai & & 48 & 46 & 96 \\
\hline 2 & A Fernanda e o José & & 46 & 45 & 98 \\
\hline
\end{tabular}

Sujeito.J

\begin{tabular}{|c|c|c|c|c|c|}
\hline I & Mamaje e papai & & 48 & 48 & 100 \\
\hline 2 & A Fernanda e o José & & 46 & 45 & 98 \\
\hline
\end{tabular}

Nas duas últimas linhas da Tabela 2 encontram-se as porcentagens de leitura dos sujeitos J e F. O percentual acima de $95 \%$ de leitura correta nos dois textos apresentados indica que o desempenho dos sujeitos ficou sob o controle do texto. F, no inicio da leitura, disse que não conseguirialer, mas a experimentadora insistiu e o sujeito leu o texto completo. dela (conversa com os pais e professores) confirmam estes resultados. Observações não sistemáticas em sala de aula e informações dos professores apontam que ocorreu algum tipo de generalização nesse contexto.

Três sujeitos (M, F e J), dos cinco que participaram da pesquisa, apresentaram leitura e escrita corretas, tanto no nível textual como no 
nível de generalização. Os outros dois (B e D) apresentaram apenas leitura textual. Com M, F e J não houve necessidade de repetir nenhuma das sessões de exclusão, pois sempre conseguiram atingir o critério de leitura correta em apenas uma sessão de exclusão. $F$, nas primeiras exclusões, dizia que era difícil e sempre queria que a experimentadora desse dicas mas estas não eram fornecidas, a não ser aquelas que faziam parte do procedimento; nestas ocasiões, a experimentadora dizia para o sujeito que iria conseguir, pois é inteligente. Este comportamento foi se modificando, com o sujeito tendo mais confiança em suas respostas. Todas as exclusões, emseus aspectos gerais, apresentam características de um processo de aprendizagem, com maior incidência de erros no início do procedimento e diminuição progressiva à medida que o procedimento foi se desenvolvendo e chegando ao seu final.

M foi o sujeito que apresentou melhor desempenho durante todas as fases do programa, ou seja, o percentual de $80 \%$ de leitura correta (área critério) foi atingido mais rapidamente, além de ter lido frases completas a partir da Excl 14. Considerou-se, portanto, que já seria possível trabalhar com pequenos textos uma vez que sualeiturajáera adequada em relação a palavras isoladas e frases.

Em relação ao desempenho de J, nas primeiras tentativas em que apareceram palavras de generalização, este pedia à experimentadora para Ihe dar dicas e falar se estava certo ou errado, mas ela informava que não poderia falar nada; esse tipo de solicitação ocorreu apenas nas primeiras exclusões; depois do quinto dia de aplicação do procedimento não houve mais perguntas.

O sujeito $B$ foi o que apresentou mais dificuldade na aquisição da leitura, o que pode ser verificado pelo maior número de sessões realizadas; foram necessárias, emmédia, de três a quatro sessões para atingir o critério de passagem de uma exclusão para outra. Um fator que pode estar relacionado com a dificuldade na aquisição foi o número de faltas, pois, quando sua presença era mais freqüente, o desempenho era melhor. Quando terminou o ano letivo, o procedimento foi interrompido por um mês. $\mathrm{Na}$ volta às aulas, foi aplicado um teste de retenção e B não respondia, dizendo que tinha esquecido as palavras que tinha aprendido, resultando, deste modo, num padrão de desempenho instável. A porcentagem de acertos, que girava em tomo de $80 \%$ antes da interrupção, diminuiu para o nível do acaso, ou seja, $50 \%$, indicando que seu desempenho foi inferior ao período anterior. Em vista dessa dificuldade, foram realizadas sessões de retreino das palavras de ensino (desde a Linha de Base até a EXC 8).

Os sujeitos B e D participaram do procedimento em condições diferentes dos demais. Não apenas pela idade (9 e 12 anos), como pelo comportamento que apresentavam em sala de aula: D, segundo a professora, atrapalhava a aula e $B$ passava quase despercebido, pois não falava nada. Na escola onde D estudava, havia, inclusive, um certo consenso entre os professores de que ele não teria condições de aprender; a orientadora pedagógica, mostrando-se impotente frente ao quadro apresentado, encaminhou-o para avaliação. O período de interrupção praticamente não afetou o desempenho de $\mathrm{D}$, contrariamente ao que ocorreu em relação ao desempenho de $B$.

Os percentuais de acerto dos sujeitos $\mathrm{J}$ e $\mathrm{F}$ situam-se quase que exclusivamente na faixa de 90 a 100 por cento. Pode-se verificar que o desempenho foi melhor quando foram apresentadas apenas as palavras de ensino. Foi nítida a diferença entre os sujeitos $D$ e $B$ em relação aos demais, principalmente pelo fato de não terem apresentado generalizações.

O desempenho nas etapas de aprendizagem foi muito semelhante para todos os sujeitos, ou seja, os percentuais de acerto situam-se quase que exclusivamente dentro da área critério, indicando, dessa forma, a eficácia do procedimento. Porém, o desempenho na leitura das palavras de generalização é diferente para o conjunto dos sujeitos. O desempenho de D e B é 
praticamente nulo. O desempenho de Fé também parecido com o desempenho de J, exceto nos testes de generalização, onde ocorre uma diminuição do percentual de acertos para F.

Nos testes de equivalência, o desempenho é praticamente o mesmo para todos os sujeitos, ou seja, responderam às relações $\mathrm{BC}$ e $\mathrm{CB}$ com $90 \mathrm{a}$ 100 por cento de acerto, indicando, desse modo, queesses sujeitos passaramaler aquelas palavras com compreensão, o que permite "analisar a leiturae aescrita como um conjunto de repertórios interligados", conforme afirmam Sidman e Cresson (1973) e Mackay e Sidman (1984).

No presente estudo, além do uso de fichas como reforçadores, com os sujeitos $D e$ B, o uso das expressões verbais "muito bem", "correto" também funcionou como reforçador. Para os sujeitos $F, J$ e $M$, contudo, não foi necessário o uso de fichas; as expressões verbais utilizadas como reforçadores foram suficientes para manter o desempenho dos sujeitos sob controle do procedimento.

Como foi descrito nas páginas anteriores, os sujeitos foram capazes de realizar o que foi solicitado pela experimentadora nas atividades de ensino, chegando ao final do procedimento com um percentual médio acima de $80 \%$ de leitura correta, facilitando com isso a generalização de leitura das palavras pelos sujeitos J, F, M. No final do procedimento, o sujeito $D$, embora não tenha conseguido ler as palavras completas, estava lendo as letras das palavras de generalização; B dizia que desconhecia as palavras, não apresentando qualquer indício de leitura.

Nos três testes extensivos de leitura apresentados durante e no final do procedimento, todosos sujeitosapresentaramelevado percentual de leitura correta das palavras de ensino. Em relação às palavras de generalização, De B não conseguiram apresentar leitura correta, enquanto que os demais sujeitos (J,Fe M), além de terem generalizado, leram textos completos. Em relação aos textos apresentados pela experimentadora, $\mathrm{M}$ conseguiulere responder às perguntas; o mesmo aconteceu com JeFnosdoistextosquelhesforam apresentados. O sujeito F que, no início do procedimento, não lia, ao final realizou a leitura de uma frase que a professora estava fazendo em sala com todos os alunos (Sou fada). O sujeito J foi observado lendo, durante uma prova de matemática, 0 título de um exercício (Faça as continhas). M apresentava o que a professora classificou como uma leitura com dificuldades, ou seja, uma leitura incompleta, além de não conseguir acompanhar os colegas da turma; mesmo assim, conseguiu realizar a leitura de um pequeno texto que estava no quadro (O Tuim ficará sempre em liberdade) no momento em que a professora estava ensinando verbos (pousar, conhecer, mudar, dormir). $B$, no início do procedimento, não escrevia o que a professora passava no quadro, não pedia ajuda e deixava incompleta a atividade solicitada pela professora; contudo, durante o procedimento, leu, junto coma professora, uma palavra que estavana lousa e a copiou ("abelha").

Que fatores podem estar dificultando a inserção da criança com deficiência física na escola regular? Um deles - e talvez o mais visível - é o preconceito da aparência: são considerados incapazes de aprender pelo fato de não andareme não conseguirem pegar um lápis e escrever como as demais crianças. Oque mais assusta os professores, ao receber um aluno diferente dos padrões de normalidade, é se perceberem não preparados para trabalhar com este tipo de problema. Os professores, no início do ano, apresentavam muita dificuldade em trabalhar com uma criança com PC; até mesmo sentiam pena pela condição física dos sujeitos, questionando como uma criança dessas poderiaacompanhar os conteúdos como os demais alunos. "Mas hoje vejo como estou encantada, pois tenho outros alunos normais que não conseguem aprendercomo F...", declarou suaprofessora. Já os demais professores apenas afirmaram que houve mudança no seu processo de aprendizagem, mas ainda os vêem com dificuldade de acompanharosdemaisalunos. "Aescolanecessita aprender, antes de mais nada, a convivercom as diferenças existentes. As práticas pedagógicas continuam contribuindo para reafirmar equivo- 
cadamente que o fracasso escolar deve-se à inferioridade de condições de vida das populações marginalizadas" (Carneiro, 1996).

Outro provável fator é a segregação dos contextos de interações sociais que, por falta de modelo e contingências sociais apropriadas, produz uma linguagem oral desarticulada; tais evidências apontam para a necessidade de intervenção junto a esses indivíduos, no sentido de estabelecer, em contextos de interações sociais, vínculos afetivos com o adulto, de tal forma que esse contexto possa propiciar contingências apropriadas para a aprendizagem da linguagem (Nunes e cols., 1989). Esses indivíduos necessitam de que se estimule a realidade, tanto quanto a escrita, ainda quando a rede pública de ensino coloque em dúvida sua capacidade de aprender; paraisso, énecessário que se levem em consideração as diferenças individuais, sejam elas raciais, motoras ou até mesmo religiosas. Se não bastassem todos esses preconceitos, essas crianças têm que enfrentar, ainda, a barreira arquitetônica que, muitas vezes, as impede de freqüentar determinados prédios escolares com regularidade.

Em vista disso, pode-se perguntar: 1) Procedimentos específicos de ensino realizados fora da sala de aula (como ocorreu no presente estudo) favoreceriam o surgimento de comportamentos de interaçãoacadêmica (comotexto, com o professor e/ou colegas) em sala de aula, por crianças com seqüelas motoras? 2) Que contribuições específicas os procedimentos de matching podem oferecer para compreender os processos de leitura e escrita que ocorrem no contexto dasala de aula, em beneficio do aproveitamento acadêmico de alunos e professores que deles participam?

O presente procedimento parece ter contribuído para a melhora da leitura em sala de aula (a professora afirmou: "Multimamente não reclama para fazer a leitura em sala de aula, em alguns momentos pede para responder questões e antes eu tinha que pedir a sua opinião"). A mãe de $M$ também afirmou que, em casa, não reclama mais quando tem que ler um texto grande ("Apenas eu acho que lê muito devagar").

A pergunta que fica é: que aspectos do procedimento de discriminação condicional foram responsáveis por estas alterações? Uma possibilidade é a alteração do aspecto motivacional das crianças. Elas foram "percebendo", no desenrolar do procedimento, que "acertavam"quase tudo, eé possível que essa alteração motivacional as tenha tomado mais "autoconfiantes" em relação à leitura de palavras que não conseguiam, até então, realizar em sala de aula.

Outro fator foi a familiarização com as palavras utilizadas, o que pode ter' contribuído para facilitação da leitura. Esta foi uma preocupação do educador Paulo Freire no seu método de alfabetização, no qual as palavras a serem ensinadas são escolhidas dentro do universo vocabular do sujeito, como foram as palavras dessa pesquisa. A escolha das palavras dentro desse universo permitiu analisar a leitura e a escrita como um conjunto de repertórios interligados tal como também Sidman e Cresson (1973) e Mackay e Sidman (1984).

Permanece, ainda, uma pergunta a ser respondida: será que essas crianças que foram e continuam sendo estigmatizadas pela aparência física, tendo dificuldades de aprendizagem em sala de aula e com histórias de fracasso escolar, acompanhariam o sistema tradicional de ensino? No entender da experimentadora, procedimentos que lidem com problemas dessa natureza, como o aqui relatado, tomam-se necessários para lidar com este tipo de comportamento. 


\section{Referências Bibliográficas}

Carneiro, M.S.C. (1996). Do ensino especial ao ensino regular: tentativas de integração escolar de alunos considerados portadores denecessidades educativas especiais. Dissertação de mestrado UFSC.

de Rose, J. C.C., Souza, D. G. , Rossito, A. L., \& de Rose, T. M. S. (1992). Stimulus equivalence and generalization in reading after matching to sample by exclusion. In: S. Hayes \& L. P. Hayes (Orgs.), Understanding verbal relations (pp. 69-82). Reno, EUA: Context Press.

Freire, P. (1978). Pedagogia do oprimido (pp. 110-113).Rio de Janeiro: Paze Terra.

Mackay, H. A. (1991). Stimulus equivalence: Implications for the development of adaptive behavior [Trabalho completo]. In: B. Remington (Org.), The challenge of severe mental handicap: $A$ behavior analytic approach (pp. 235-259). London, England: John Wiley e Sons.

Mackay, H.A., \& Sidman, M. (1984).Teaching new Behavior via equivalence relations [Trabalho completo]. In: P.H. Brooks, R. Sperber \& C.Mac Cauley (Orgs.), Learning and cognition in the mentally retarded hillsdale (pp. 493-513) N. J.: Erbaum.

Mackay, H.A. (1985). Stimulus equivalence in rudimentary reading and spelling. Analysis and Intervention in Developmental Disabilities, 5, 373-387.

Matos, M.A., \& d' Oliveira, M.M.H. (1992). Equivalence relations and reading. In: S.C. Hayes (Orgs.), Understanding verbal relations (pp. 83-94). Reno (EUA): Context Press.

Medeiros, J.G., Bittelbrum, E., Domit, M., Gonçalves, M.D. da S. \& Caetano, S.S. (1996). Condições que facilitam a aprendizagem de leitura e escrita em crianças com história de fracasso escolar [Resumo]. In: Sociedade Brasileira de Psicologia (Org.), Resumos de comunicações científicas da III Reunião Especial da SBPC (p. 539). Florianópolis: SBPC.
Medeiros, J.G., \& Monteiro, G. (1996). Modificação de comportamento de uma criança com distúrbio de déficit de atenção com hiperatividade com a participação dos familiares: um estudo de caso [Resumo].In: Sociedade Brasileira dePsicologia(Org.), Resumos de comunicações científicas da III Reunião Especial da SBPC (p. 527). Florianópolis: SBPc.

Medeiros, J.G., Monteiro, G.,\& Silva, K. Z. (1997). Aquisição de leitura e escrita por um sujeito adulto. Temas em Psicologia, 1, 65-78.

Melchiori, L, Souza, D., \& de Rose, J.C. (1992). Aprendizagem da leitura por meio de um procedimento de discriminação sem erros (Exclusão): uma replicação com pré-escolares. Psicologia: Teoria e Pesquisa, 8(1),101- 111.

Nunes, L. R., Conceição, S., Aguiar, F., Garcia, A.V., \&Duarte, G. (1989). The use of incidental teaching procedures to develop oral language in language-delayed preschoolersataday care center [Trabalho completo]. In: $15^{a}$ ConvençãoAnual da Association for Behavior Analysis (Org.). Milwaukee (EUA): ABA.

Sidman, M. (1971). Reading and auditory-visual equivalences. Journal of Speech and Research, 14, 5-13.

Sidman, M. eCresson, 0.(1973). Reading and crossmodal transfer of stimulus equivalences in severe mental retardion. American Journal of mental Deficiency, 77, 515-523.

Stoddard, L T. (1992). Stimulus equivalence as a basis for integrating language arts instruction [Trabalho completo]. In: XVIII Convenção Anual da Association for Behavior Analysis (Org.). San Francisco (EUA): ABA.

Stromer, R., Mackay, H. A. e Stoddard, LT. (1992). Classroom applications of stimulus equivalence technology. Journal of Behavioral Education, 2, 225-256. 